\title{
Association between Medicaid expansion status and lung cancer screening exam growth: findings from the ACR lung cancer registry.
}

\author{
Neal Gupta \\ Thomas Jefferson University \\ Ethan J. Halpern \\ Thomas Jefferson University \\ Vijay M. Rao \\ Thomas Jefferson University
}

Follow this and additional works at: https://jdc.jefferson.edu/radiologyfp

Part of the Radiology Commons

Let us know how access to this document benefits you

\section{Recommended Citation}

Gupta, Neal; Halpern, Ethan J.; and Rao, Vijay M., "Association between Medicaid expansion status and lung cancer screening exam growth: findings from the ACR lung cancer registry." (2020). Department of Radiology Faculty Papers. Paper 98.

https://jdc.jefferson.edu/radiologyfp/98

This Article is brought to you for free and open access by the Jefferson Digital Commons. The Jefferson Digital Commons is a service of Thomas Jefferson University's Center for Teaching and Learning (CTL). The Commons is a showcase for Jefferson books and journals, peer-reviewed scholarly publications, unique historical collections from the University archives, and teaching tools. The Jefferson Digital Commons allows researchers and interested readers anywhere in the world to learn about and keep up to date with Jefferson scholarship. This article has been accepted for inclusion in Department of Radiology Faculty Papers by an authorized administrator of the Jefferson Digital Commons. For more information, please contact: JeffersonDigitalCommons@jefferson.edu. 
Association between Medicaid Expansion Status and Lung Cancer Screening Exam Growth:

Findings from the ACR Lung Cancer Registry

Neal Gupta, MD (a), Ethan J. Halpern, MD (a) and Vijay M. Rao, MD (a)

Figures: 3

Tables: 3

(a) Department of Radiology, Thomas Jefferson University Hospital, Philadelphia, Pennsylvania

Author Declarations:

Conflicts of Interests:

No conflicts of interests exist.

Funding:

No funding was received for this work.

Acknowledgments:

The authors wish to thank Dr. Daniel Polsky, PhD, for his critical review and helpful discussions regarding the manuscript.

Figure 1 was rendered using https://mapchart.net/usa.html.

Corresponding author and reprints: Neal Gupta, MD, 132 South 10th Street, Main Building, Thomas Jefferson University Hospital, Department of Radiology, Philadelphia, PA 19107; email: neal.gupta@jefferson.edu, (215) 503-4121 

Abstract

Purpose: To determine if Medicaid expansion is associated with increased volumes of lung cancer screenings.

Methods: A quasi-experimental study was performed to compare the annual growth rates in lung cancer screenings between states that expanded Medicaid $(n=31)$ versus those that did not $(\mathrm{n}=17)$. Using the American College of Radiology Lung Cancer Screening Registry, we calculated the average annual growth rate between 2016-2019 for both groups. Secondary analyses between these two groups also included calculations of the percentages of studies considered appropriate by USPSTF criteria.

Results: No significant difference was identified in the average annual growth in lung cancer screenings between Medicaid expanding and non-expanding states $(57.6 \%, 50.3 \%, \mathrm{P}=.51)$. No difference was observed in the percentage of studies considered appropriate (Medicaid expanding $=89.6 \%$, non-expanding $=90.2 \%, \mathrm{P}=.72$ ). At baseline, there were socioeconomic differences between both groups of states. Medicaid expanding states had a more urban population $(76.5 \%$ versus $67.9 \%, \mathrm{P}=0.05)$ and higher average incomes $(\$ 56,947, \$ 49,876$, $\mathrm{P}<0.05)$.

Conclusion: No association is found between Medicaid expansion and increasing volumes of lung cancer screening exams. Although no data is available in the registry for screening exams before the implementation of Medicaid expansion (2014), most nationwide estimates of lung screening rates report a low baseline $(<5 \%)$. Furthermore, despite being advantaged in other ways, such as with a more urban population or with higher incomes, the Medicaid expansion cohort does not demonstrate a higher growth rate. These findings suggest Medicaid expansion alone will not increase lung cancer screenings. 
Keywords: Medicaid, Lung Cancer screenings, Utilization 


\section{Introduction}

A principal objective of the Affordable Care Act (ACA) was to decrease the number of uninsured adults in America (1). Unique among the developed world, America still does not guarantee health insurance coverage for everyone (2). The ACA worked towards a goal of universal coverage through the expansion of Medicaid. Traditionally, this government-sponsored healthcare scheme covered children, pregnant women and adults with disabilities. Under Medicaid expansion, states could offer coverage to any previously uninsured adult with an income below $138 \%$ of the poverty line $(3,4)$.

However, based on the Supreme Court's judgment on the Affordable Care Act, it is the prerogative of individual states to decide whether to participate in Medicaid expansion (5). As of July 2020, 13 states have still not adopted Medicaid expansion and two have yet to implement their program (6). Medicaid expansion is partly controversial because although extending coverage to the uninsured is generally agreed to be positive (with benefits that extend beyond health status), its effects on improving patient outcomes remain a source of debate.

To date, only two randomized controlled trials have examined the effects of extending health care benefits on patient outcomes, the RAND Corporation Health Insurance Experiment (1971-1986) and the Oregon Health Insurance Experiment (2008). Both studies demonstrated individuals provided health coverage did not always have better outcomes compared to the uninsured (7-11). Medicaid expansion's effects on the utilization of screening exams remain a matter of continued investigation with mixed results. Several studies have found an association between Medicaid expansion and increased mammography, cervical cancer screening and colorectal cancer screenings (12-13). However, other studies have not found a significant increase in screening rates (14-15). All of these studies relied on indirect means for assessing 
screening utilization, most often through nationwide survey data. No study has yet assessed the association between Medicaid expansion and lung cancer screening.

Our study seeks to examine the association between Medicaid expansion under the Affordable Care Act and the growth rate of lung cancer screenings. In 2013, the United States Preventive Services Task Force (USPSTF) recommended annual screening with low dose CT among adults 55 to 80 years who have a 30 pack-year smoking history and currently smoke or have quit within the past 15 years (16). Despite the recommendation, lung cancer rates among eligible individuals remain exceedingly low compared to other preventative screening studies such as mammography and colonoscopies. For example, in 2015, it was estimated that only $3.9 \%$ of eligible individuals received a lung cancer screening versus $64 \%$ for mammography and $60 \%$ for endoscopy (17-18).

Furthermore, the Medicaid population represents a particularly high-risk group for lung cancer, with nearly double the rate of smoking compared to privately insured individuals (19). The Medicaid population has not recorded similar declines in smoking rates compared to the general population (20). The existence of a link between Medicaid expansion and increased lung cancer screening rates has not been studied (21-22). States which expand Medicaid are expected to record a lower uninsured population. We hypothesize that this improved insurance coverage will result in a higher growth rate in screenings compared to states that chose not to expand and continue to have a higher uninsured population. Underlying this faster growth would be improved access to the healthcare system among the previously uninsured.

2. Materials and Methods

2.1 Study Population 
Because Medicaid expansion is a voluntary decision at the state level, the different decisions of various states provide an opportunity to compare the increase in the number of lung cancer studies among states that adopted Medicaid expansion $(n=31)$ versus those that chose not to participate $(\mathrm{n}=17)$. We utilize the American College of Radiology Lung Cancer Screening Registry (LCSR) to calculate the annual percentage change in lung cancer screenings for each state between 2016-2019, years for which a complete dataset is available. The LCSCR is unique in that it is a nationwide registry of accredited screening sites that perform lung cancer screenings. It was created in 2015 , is publicly available and has been used to generate national estimates of lung screening coverage rates (23). The registry reports the total number of screening exams performed by each state. It also includes secondary measures such as the percentage of studies considered appropriate by USPSTF criteria. Of note, it does not contain data on the number of individuals eligible for a screening exam.

\subsection{Data Collection and Analysis}

Because the data used is anonymized and publicly available, this study did not require institutional review board approval. To determine volumes of lung cancer screenings, we recorded statewide totals of lung cancer screenings for each year between 2016-2019. Data was tabulated on Microsoft Excel 2016 (Microsoft Corporation, Redmond, Washington). The dataset was accessed on 20 July 2020. To control the screening volumes for the population of each respective state, we calculated the number of screenings per 1000 adult smokers. We calculated the number of adult smokers in each state using publicly available United States Census statewide population data tables from 2019 and the Centers for Disease Control Behavioral Risk Factor Surveillance System Survey Data on tobacco use (24-25). 
The average yearly change in lung cancer screenings is calculated for both groups (adopting states and non-adopting states), and the difference between these two groups was evaluated for statistical significance via a student t-test. Based upon our hypothesis, the Medicaid expansion group was expected to demonstrate a higher rate of annual growth in lung cancer screenings.

The Medicaid expansion group would also be expected to record a higher increase in Medicaid coverage between 2013 and 2019 compared to the non-expansion group. In addition to comparing the growth rate for lung cancer screening exams between Medicaid expanding and non-expanding states, we conducted additional secondary analyses. We compared the percentage of lung cancer screening studies considered appropriate by USPSTF criteria for both groups. Additionally, a comparison of baseline socio-economic profiles between both groups of states was obtained, including: average income, rates and sources of insurance coverage, average percentage of the population considered white/non-Hispanic and the average percentage urban population. All of these baseline characteristics were also tested for statistical significance via a student t-test.

Data sources for the baseline socio-economic profiles of each group came from the Kaiser Family Foundation Statewide Population Distribution by Race/Ethnicity Tables (2018) and Kaiser Family Foundation Health Insurance Coverage Statewide Tables (2013, 2018, 2019). All of these datasets contain anonymized aggregate data and are publicly available for download (26-29).

Most states implemented Medicaid expansion on January 1st, 2014. However, some states adopted the expansion at a later date. During our examined period (2016-2019), Louisiana implemented Medicaid expansion in 2016 and Virginia did so in 2019 (6). For this study, 
Louisiana is considered a Medicaid expander while Virginia is regarded as a non-adopter.

Additionally, Wyoming, Utah and the District of Columbia are excluded from the study due to missing data in ACR Lung Cancer Registry. The states included in the Medicaid expansion $(\mathrm{n}=31)$ and non-expansion groups $(\mathrm{n}=17)$ are depicted in Figure 1.

In order to evaluate the initial impact of Medicaid expansion, we conducted a subset analysis involving the limited dataset from 2015 . We calculated the average growth rate during this year among 23 Medicaid expanding and 16 non-expanding states. We performed this subset analysis in order to capture any initial growth in screenings immediately following Medicaid expansion in 2014.

3. Results

Demographic differences were identified between the Medicaid expanding and non expanding states. Among the states that expanded Medicaid, there is a statistically significant higher urban population $(76.5 \%$ versus $67.9 \%, \mathrm{p}=0.05)$ and higher average incomes $(\$ 56,947$, $\$ 49,876, \mathrm{P}<0.05)$. The percentage of the population considered ethnic minorities is not different between both groups (Table 1). Between 2013-2019, the population covered by Medicaid increased by $21.1 \%$ in the expanding group versus $-0.7 \%$ in the non-expanding group (p= <0.001). In 2018, the states in the non-expanding cohort had a higher uninsured population $(10.6 \%)$ compared to the expanding cohort $(6.6 \%)(\mathrm{p}=<0.001)$. The Medicaid covered population was also higher in the expansion group $(21.4 \%$ vs $17.1 \%, \mathrm{p}=<0.001)$ (Table 2$)$.

A comparison of Medicare coverage demonstrated no significant difference in the percentage of population covered by Medicare between expanding and non-expanding states, at 14.7 and $14.4 \%$ ( $P=0.6)$. Additionally, between 2013-2018, there was no significant change in the proportion of the population covered by Medicare $(+11.2,+11.2 \%, \mathrm{p}=1.0)$. Other sources of 
insurance coverage, including private and military insurance did not significantly differ between both groups (expanding versus non-expanding; 57.3\% and 57.4\%, $\mathrm{p}=0.9$ ) (Table 2).

Our study consists of a total of 1,563,590 screenings. Figures 2 demonstrates a sustained increase in the volume of lung cancer screening performed for both groups between 2016-2019. Starting from a low base in 2016, both groups showed similar average annual increases in lung cancer screenings for the duration of this study (Figure 3). No yearly increase in screening exams was statistically significant $(\mathrm{p}=0.07,0.9,0.7)$ for years $2016-2017,2017-2018$ and $2018-2019$ respectively. Between 2016-2019 the average annual increase in screenings was $57.6 \%$ for the Medicaid expanding group and $50.3 \%$ for the non-expanding group, an overall difference that is not statistically significant ( $\mathrm{p}=0.5$ ) (Table 3 ). In the subset analysis involving the limited dataset from 2015, the average annual increase for the Medicaid expansion group $(\mathrm{n}=23)$ was $510 \%$ versus $418 \%$ in the non-expanding group $(\mathrm{n}=16)$, which is also not statistically significant $(\mathrm{P}=0.5)$. Finally, during this study, the percentage of exams considered appropriate by USPSTF criteria was $89.6 \%$ in the Medicaid expansion group and $90.2 \%$ in the non-expanding group (Table 3). These results are not significantly different and did not vary throughout the examined time frame $(\mathrm{p}=0.7)$.

\section{Discussion}

We found no association between Medicaid expansion and increased volumes of lung cancer screenings between 2016-2019. However, the states that did expand Medicaid demonstrated a higher rate of insurance coverage compared to the non-expanders. Medicaid expansion, although associated with improved insurance coverage, is not associated with a faster rate of growth in lung cancer screenings. 
The ACR LCSR contains aggregate data on the total number of screenings performed in each state, regardless of the insurance payor. Since lung cancer screenings include the population aged 65-80, Medicare would be the primary source of payment for that age group. Differences in the percentage of the population covered by Medicare in our two groups would also cause differences in the volumes of lung cancer screenings. However, our data demonstrates the percentage of the population covered by Medicare is the same between both groups and did not change during the study period. The percentage of the population covered by private insurance and military insurance also does not significantly vary between both groups.

It is possible that the Medicaid and uninsured population do not represent a significant portion of the eligible screening population. However, a 2015 estimate of the lung cancer screening population determined among all 6.8 million eligible smokers, a majority were either uninsured or Medicaid covered. Indeed, this eligible population was greater than that covered by Medicare or private insurance (30).

It is also important to note the variability in Medicaid coverage of lung cancer screenings. Twelve states require patients to pay for the screening exam for patients aged 55-64. Of these states, two were excluded from our study (Utah and Wyoming) and two were included in the Medicaid expanding group (Louisiana and Nebraska). The remaining eight states were all in the non-expansion group (31). This pattern would tend to favor the Medicaid expansion states. Some states also require pre-authorization before covering the exam (including CO, CT, IW, NY, NC, PA, VT, WA and WV in the Medicaid expanding cohort). However, even with barriers of preauthorization or copayment, one would still expect insured patients to be more likely to receive a screening test than uninsured.

\subsection{Limitations}


Given our study design, we cannot conclude with absolute certainty that Medicaid expansion does not increase lung cancer screenings. Our primary limitation is the absence of data prior to the implementation of Medicaid expansion (year 2013). Because the USPSTF recommendation was made in 2013, Medicaid expansion was primarily enacted in 2014 and the registry was created in 2015 , such data is not available. We attempt to ameliorate the impact of this limitation in several ways. Based on previously published estimates of national lung cancer screening rates, we can assume a low national baseline in screening rates. Indeed, multiple studies report less than $5 \%$ of eligible individuals have ever received a lung cancer screening 23,32-34). Furthermore, our study can partly account for the 2015 year with a limited dataset that demonstrates no significant differences between both groups.

As an additional limitation, there are potentially unobservable differences that could impact lung cancer screenings rates. The Medicaid expanding cohort is favored with a more urban population which should increase the availability of local screening centers. It has been demonstrated that there is a disparity between urban and rural areas in the availability of lung cancer screening sites (35). Thus, the urban population in the expanding states might be expected to bias that group in favor of greater lung cancer screening. Medicaid expanding states are also favored with higher average incomes.

A strength of this study is that it draws on the data from the LCSR, allowing for unique analysis that draws on nationwide data for lung screenings and includes all insurance payers. Furthermore, it can assess the percentage of exams conducted that meets USPSTF criteria. The lack of difference in appropriate studies between both groups suggests providers act similarly when ordering lung cancer screening tests and are correctly reaching the eligible population.

\section{Conclusion}


Hence, even though Medicaid expansion states are already advantaged in other ways compared to the non-expansion group, we are still not able to identify an increased rate of growth in screening exams. This finding is reinforced in the setting of a low nationwide baseline screening rate and the lack of differences in provider practice between both groups. It is also remarkable compared to other screening exams which do demonstrate a higher screening rate between the Medicaid covered and uninsured population. As a comparison, the use of mammography screening has successfully increased from under 40\% in 1987 to nearly $60 \%$ in 2003. This increase in screening has been achieved by a variety of public health initiatives that sought to increase the awareness of screening. For example, the National Breast and Cervical Cancer Early Detection Program first created in 1990 has successfully targeted high risk individuals for cervical and mammogram screenings. Furthermore, among the highest risk minorities, multifaceted interventions that incorporated same day mammography appointments, free screenings and transportation tend to report the highest increase in screening rates $(18,36-$ $38)$.

Therefore, our study suggests Medicaid expansion alone is not likely to increase lung cancer screening rates. Other initiatives, such as public health awareness campaigns that specifically target the most at-risk individuals, may be necessary to improve the screening rate for this underutilized exam. 
References

1. Garrett, A. Bowen, and Anuj Gangopadhyaya. "Who gained health insurance coverage under the ACA, and where do they live?." Urban Institute, ACA ImplementationMonitoring and Tracking (2016).

2. Vladeck, Bruce. "Universal health insurance in the United States: Reflections on the past, the present, and the future." (2003): 16-19.

3. Courtemanche, Charles, James Marton, and Aaron Yelowitz. "Who gained insurance coverage in 2014, the first year of full ACA implementation?." Health Economics 25.6 (2016): 778-784.

4. Sommers, Benjamin D., et al. "Changes in self-reported insurance coverage, access to care, and health under the Affordable Care Act." Jama 314.4 (2015): 366-374.

5. Gostin, Lawrence O. "The Supreme Court's historic ruling on the Affordable Care Act: economic sustainability and universal coverage." JAMA 308.6 (2012): 571-572.

6. Henry J Kaiser Family Foundation. Status of state action on the Medicaid expansion decision. Published in 2020. Accessed July 4, 2020. <https://kff.org/health-reform/stateindicator/state-activity-around-expanding-medicaid-under-the-affordable-care-act/>

7. Aron-Dine, Aviva, Liran Einav, and Amy Finkelstein. "The RAND health insurance References experiment, three decades later." Journal of Economic Perspectives 27.1 (2013): 197-222.

8. Brook, Robert H., et al. "The effect of coinsurance on the health of adults: results from the RAND Health Insurance Experiment." (1984).

9. Baicker, Katherine, et al. "The impact of Medicaid on clinical outcomes: evidence from the Oregon Health Insurance Experiment." N Engl J Med 368.18 (2013): 1713-1722

10. Baicker, Katherine, et al. "The effect of Medicaid on management of depression: evidence from the Oregon Health Insurance Experiment." The Milbank Quarterly 96.1 (2018): 29-56

11. Taubman SL, Allen HL, Wright BJ, Baicker K, Finkelstein AN. Medicaid increases emergency-department use: evidence from Oregon's health insurance experiment. Science 2014;343:263-8 
12. Hendryx, M., \& Luo, J. (2018). Increased cancer screening for low-income adults under the Affordable Care Act Medicaid expansion. Medical care, 56(11), 944-949.

13. Toyoda, Y., Oh, E. J., Premaratne, I. D., Chiuzan, C., \& Rohde, C. H. (2020). Affordable Care Act State-Specific Medicaid Expansion: Impact on Health Insurance Coverage and Breast Cancer Screening Rate. Journal of the American College of Surgeons.

14. Huguet, N., Angier, H., Rdesinski, R., Hoopes, M., Marino, M., Holderness, H., \& DeVoe, J. E. (2019). Cervical and colorectal cancer screening prevalence before and after Affordable Care Act Medicaid expansion. Preventive medicine, 124, 91-97.

15. Fedewa, S. A., Yabroff, K. R., Smith, R. A., Sauer, A. G., Han, X., \& Jemal, A. (2019). Changes in breast and colorectal cancer screening after Medicaid expansion under the Affordable Care Act. American journal of preventive medicine, 57(1), 3-12.

16. Moyer, Virginia A. "Screening for lung cancer: US Preventive Services Task Force recommendation statement." Annals of internal medicine 160.5 (2014): 330-338.

17. Smith, Robert A., et al. "Cancer screening in the United States, 2019: A review of current American Cancer Society guidelines and current issues in cancer screening." CA: a cancer journal for clinicians 69.3 (2019): 184-210.

18. Armstrong, Katrina, et al. "Using lessons from breast, cervical, and colorectal cancer screening to inform the development of lung cancer screening programs." Cancer 122.9 (2016): 1338-1342.

19. Centers for Disease Control and Prevention. "Smoking rates for uninsured and adults on Medicaid more than twice those for adults with private health insurance." Centers for Disease Control and Prevention (2015).

20. Zhu, Shu-Hong, et al. "Smoking prevalence in Medicaid has been declining at a negligible rate." PloS one 12.5 (2017): e0178279

21. Guth, Madeline, Rachel Garfield, and Robin Rudowitz. "The effects of Medicaid expansion under the ACA: updated findings from a literature review." Kaiser Family Foundation (2020).

22. Mazurenko, Olena, et al. "The effects of Medicaid expansion under the ACA: a systematic review." Health Affairs 37.6 (2018): 944-950. 
23. Pham, Danh, et al. "Lung Cancer screening registry reveals low-dose CT screening remains heavily underutilized." Clinical lung cancer 21.3 (2020): e206-e211.

24. Estimates of the Total Resident Population and Resident Population Age 18 Years and Older for the United States, States, and Puerto Rico: July 1, 2019 (SCPRC-EST201918+POP-RES) U.S. Census Bureau, Population Division. Accessed 21 October 2020.

25. Current Cigarette Use Among Adults, Behavioral Risk Factor Surveillance System Survey Data. Atlanta, Georgia: U.S. Department of Health and Human Services, Centers for Disease Control and Prevention, [https://www.cdc.gov/statesystem/cigaretteuseadult.html, 2018]. Accessed 21 October 2020.

26. Health Insurance Coverage of the Total Population. Kaiser Family Foundation. Published in 2018. Accessed 20 July 2020. <https://www.kff.org/other/state-indicator/totalpopulation/?currentTimeframe $=0 \&$ sortModel=\%7B $\% 22$ colId $\% 22: \% 22$ Location $\% 22, \% 2$ 2sort\%22:\%22asc\%22\%7D\#notes>

27. Urban Percentage of the Population by State. United States Census 2010. Published in 2020. Accessed 15 May 2020. <https://www.icip.iastate.edu/tables/population/urbanpctstates>

28. Population Distribution by Race/Ethnicity. Kaiser Family Foundation. Published in 2018. Accessed 22 July 2020. <https://www.kff.org/other/state-indicator/distributionbyraceethnicity/?currentTimeframe $=0 \&$ sortModel $=\% 7 \mathrm{~B} \% 22$ colId $\% 22: \% 22$ Location $\% 22$ ,\% 22sort\%22:\%22asc\%22\%7D>

29. U.S. Bureau of Economic Analysis, "SAINC1 Personal Income Summary: Personal Income, Population, Per Capita Personal Income," [https://apps.bea.gov/itable/iTable.cfm?ReqID=70\&step=1] Accessed 25 October 2020.

30. Jemal, Ahmedin, and Stacey A. Fedewa. "Lung cancer screening with low-dose computed tomography in the United States_-2010 to 2015." JAMA oncology 3.9 (2017): 1278-1281.

31. American Lung Association. Lung Cancer Screening Coverage in State Medicaid Programs. Published in 2020. Accessed 15 March 2020. 
<https://www.lung.org/getmedia/cb086cfd-2fbb-4737-b518-e83cf1fcc411/lung-cancerscreening-1>

32. Nishi, Shawn, et al. "Use of lung cancer screening with low-dose computed tomography in the medicare population." Mayo Clinic Proceedings: Innovations, Quality \& Outcomes 3.1 (2019): 70-77

33. Richards TB, Doria-Rose VP, Soman A, et al. Lung cancer screening inconsistent with U.S. Preventive Services Task Force recommendations. Am J Prev Med 2019;56:66-73

34. Okereke, Ikenna C., et al. "Trends in lung cancer screening in the United States, 2016 2017." Journal of thoracic disease 11.3 (2019): 873.

35. Charkhchi, Paniz, Giselle E. Kolenic, and Ruth C. Carlos. "Access to lung cancer screening services: preliminary analysis of geographic service distribution using the ACR Lung Cancer Screening Registry." Journal of the American College of Radiology 14.11 (2017): 1388-1395.

36. Health Insurance Coverage of the Total Population. Kaiser Family Foundation. Published in 2018. Accessed 20 July 2020. <https://www.kff.org/other/state-indicator/totalpopulation $/$ ?currentTimeframe $=0 \&$ sortModel $=\% 7 \mathrm{~B} \% 22$ colId $\% 22: \% 22$ Location $\% 22, \% 2$ 2sort\%22:\%22asc\%22\%7D\#notes>

37. Urban Percentage of the Population by State. United States Census 2010. Published in 2020. Accessed 15 May 2020. <https://www.icip.iastate.edu/tables/population/urbanpctstates>

38. Population Distribution by Race/Ethnicity. Kaiser Family Foundation. Published in 2018. Accessed 22 July 2020. <https://www.kff.org/other/state-indicator/distributionbyraceethnicity/?currentTimeframe $=0 \&$ sortModel $=\% 7 \mathrm{~B} \% 22$ colId $\% 22: \% 22$ Location $\% 22$ ,\%

22sort $\% 22: \% 22$ asc $\% 22 \% 7 \mathrm{D}>$

39. U.S. Bureau of Economic Analysis, "SAINC1 Personal Income Summary: Personal Income, Population, Per Capita Personal Income," [https://apps.bea.gov/itable/iTable.cfm?ReqID=70\&step=1] Accessed 25 October 2020.

40. Ekwueme, D. U., Uzunangelov, V. J., Hoerger, T. J., Miller, J. W., Saraiya, M., Benard, V. B., \& Myers, E. R. (2014). Impact of the National Breast and Cervical Cancer Early 
Detection Program on cervical cancer mortality among uninsured low-income women in the US, 1991-2007. American journal of preventive medicine, 47(3), 300-308.

41. Miller, J. W., Plescia, M., \& Ekwueme, D. U. (2014). Public health national approach to reducing breast and cervical cancer disparities. Cancer, 120(S16), 2537-2539.

42. Masi, Christopher M., Dionne J. Blackman, and Monica E. Peek. "Interventions to enhance breast cancer screening, diagnosis, and treatment among racial and ethnic minority women." Medical Care Research and Review 64.5_suppl (2007): 195S-242S.

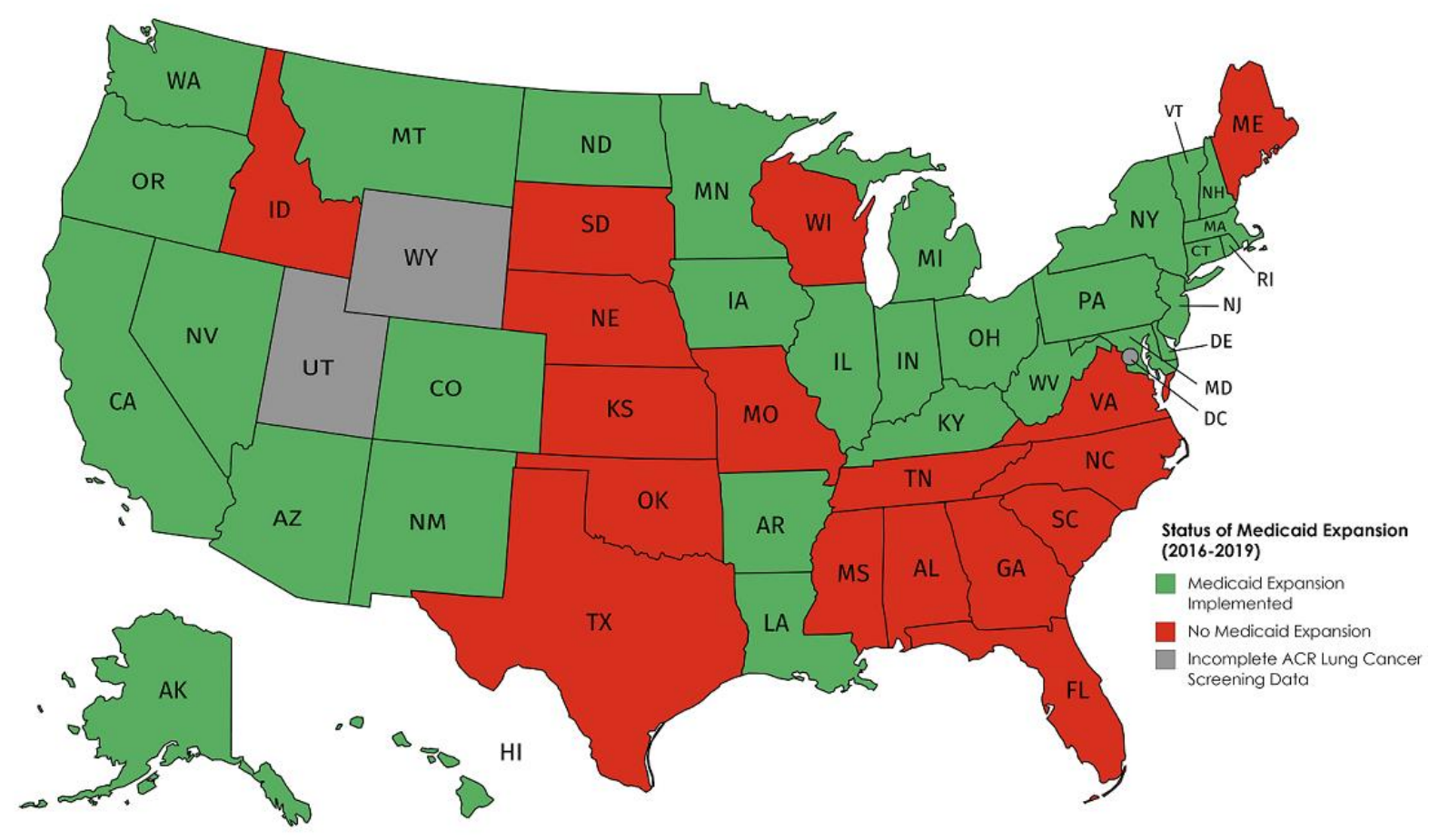

Figure 1 


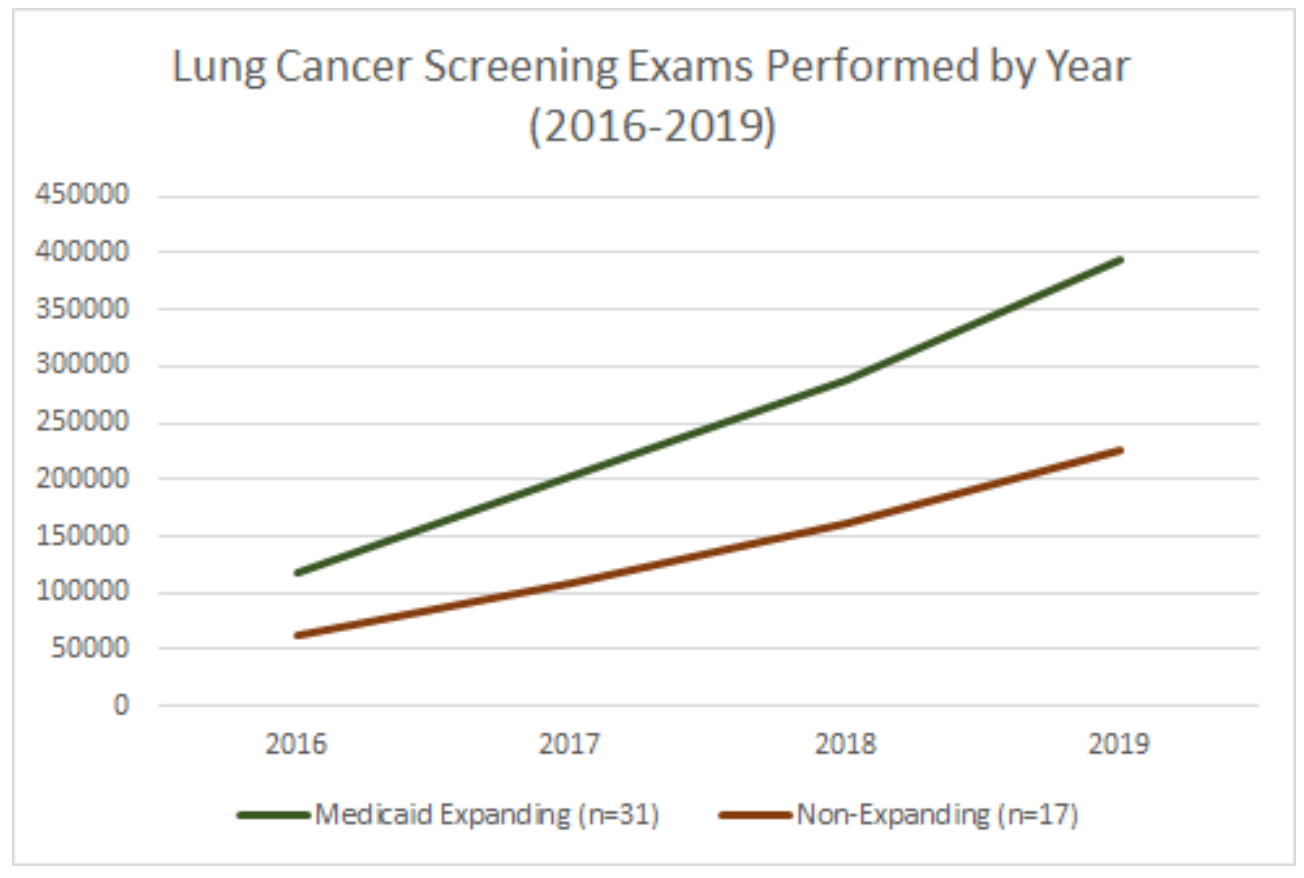

Figure 2 


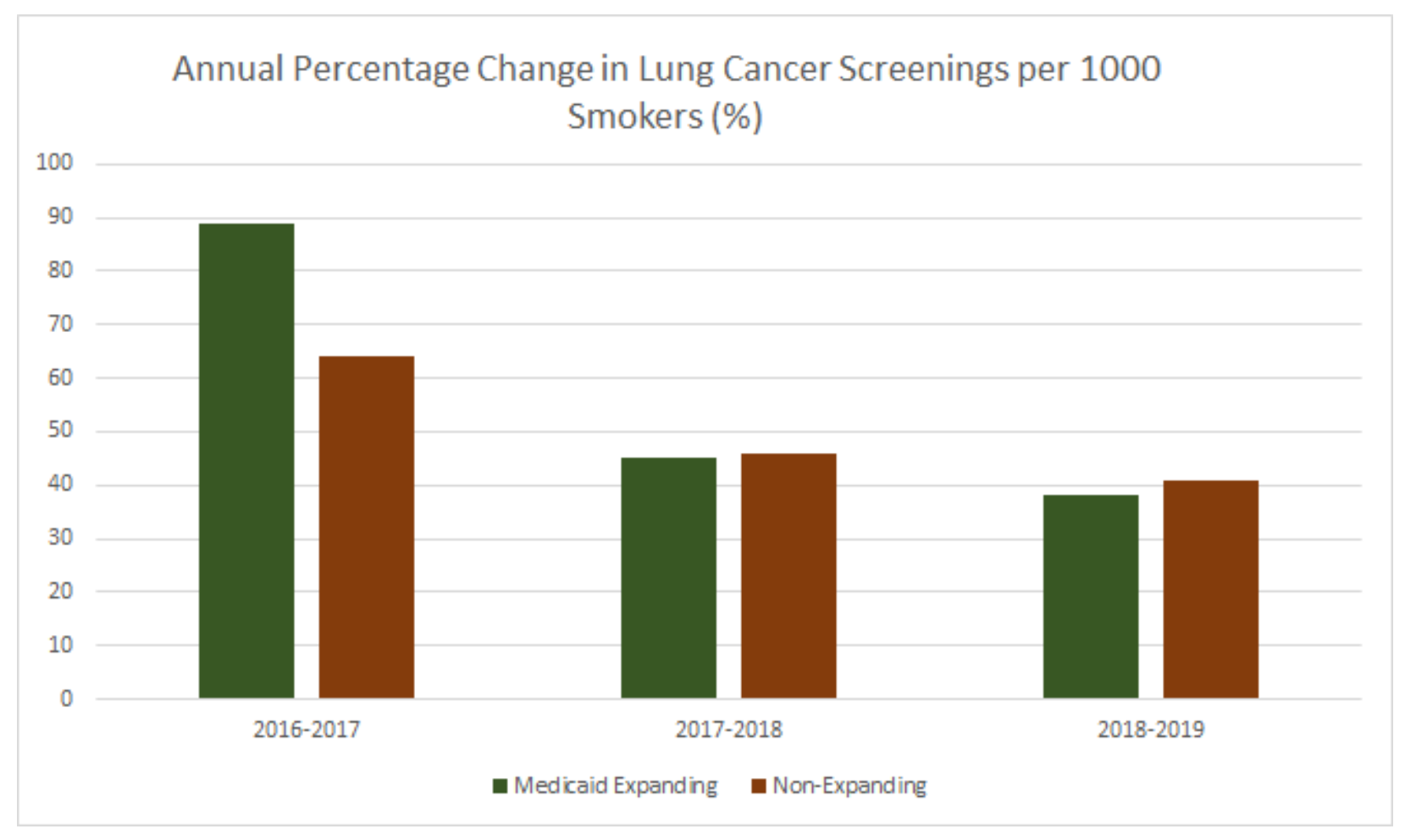

Figure 3 


\section{Highlights}

Lung cancer screening rates remain low nationwide, although the volume of screenings have rapidly increased in recent years.

Medicaid expansion is associated with improved insurance coverage, but not increased volumes of lung cancer screenings.

Medicaid expansion alone may not increase lung cancer screenings. Public health awareness campaigns may be needed to target the most at-risk individuals. 
Figure 1: State Implementation of Medicaid Expansion

Figure 2: Annual Number of Lung Cancer Screening Exams Performed by Year (2016-2019)

Figure 3: Annual Percentage Change in Lung Cancer Screenings per 1000 Smokers (2016-2019) 


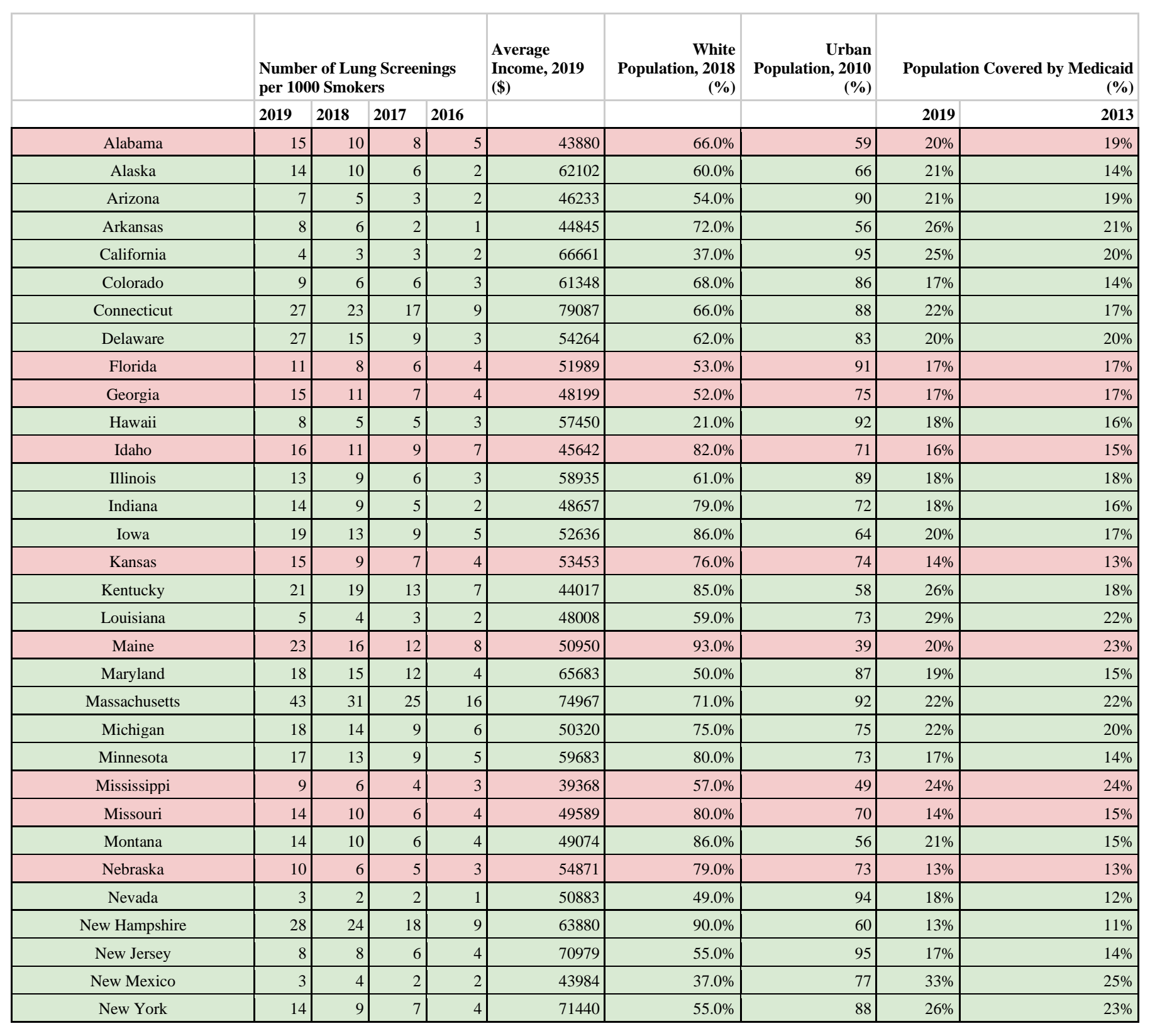




\begin{tabular}{|c|c|c|c|c|c|c|c|c|c|}
\hline North Carolina & 17 & 13 & 8 & 4 & 47803 & $63.0 \%$ & 66 & $18 \%$ & $18 \%$ \\
\hline North Dakota & 17 & 11 & 14 & 9 & 57501 & $84.0 \%$ & 60 & $12 \%$ & $10 \%$ \\
\hline Ohio & 13 & 10 & 6 & 3 & 50546 & $79.0 \%$ & 78 & $20 \%$ & $17 \%$ \\
\hline Oklahoma & 3 & 3 & 2 & 1 & 47951 & $65.0 \%$ & 66 & $17 \%$ & $17 \%$ \\
\hline Oregon & 16 & 12 & 8 & 4 & 52937 & $75.0 \%$ & 81 & $21 \%$ & $17 \%$ \\
\hline Pennsylvania & 19 & 13 & 9 & 6 & 58775 & $76.0 \%$ & 79 & $20 \%$ & $17 \%$ \\
\hline Rhode Island & 30 & 13 & 16 & 12 & 56542 & $72.0 \%$ & 91 & $21 \%$ & $17 \%$ \\
\hline South Carolina & 12 & 9 & 5 & 3 & 45314 & $64.0 \%$ & 66 & $19 \%$ & $19 \%$ \\
\hline South Dakota & 16 & 13 & 11 & 6 & 53925 & $82.0 \%$ & 57 & $13 \%$ & $15 \%$ \\
\hline Tennessee & 13 & 9 & 5 & 3 & 48761 & $74.0 \%$ & 66 & $20 \%$ & $19 \%$ \\
\hline Texas & 4 & 3 & 2 & 2 & 52504 & $41.0 \%$ & 85 & $16 \%$ & $17 \%$ \\
\hline Vermont & 35 & 31 & 23 & 13 & 56691 & $93.0 \%$ & 39 & $24 \%$ & $25 \%$ \\
\hline Virginia & 16 & 10 & 7 & 4 & 60116 & $62.0 \%$ & 76 & $14 \%$ & $11 \%$ \\
\hline Washington & 15 & 9 & 5 & 3 & 64898 & $68.0 \%$ & 84 & $20 \%$ & $15 \%$ \\
\hline West Virginia & 6 & 5 & 3 & 1 & 42336 & $92.0 \%$ & 49 & $27 \%$ & $20 \%$ \\
\hline Wisconsin & 23 & 17 & 10 & 5 & 53583 & $81.0 \%$ & 70 & $16 \%$ & $17 \%$ \\
\hline Medicaid Expanding $(\mathrm{n}=31)$ & 16 & 12 & 9 & 5 & 56947 & $67.6 \%$ & 76 & $21 \%$ & $17 \%$ \\
\hline Non-Medicaid Expanding $(\mathrm{n}=17)$ & 14 & 10 & 7 & 4 & 49876 & $68.8 \%$ & 68 & $17 \%$ & $17 \%$ \\
\hline
\end{tabular}

Table 1: Statewide Lung Cancer Screenings per 1000 Smokers and Background Socioeconomic Characteristics (US Census 2010 and 2019, Kaiser Family Foundation Statewide Distribution of Population by Race/Ethnicity 2018, Kaiser Family Foundation Statewide Insurance Tables 2013 and 2019, Bureau of Economic Analysis 2019) 
Sources of Insurance Coverage

(\% of Population Covered by

Payor, 2018)

\begin{tabular}{lllll}
\hline & $\begin{array}{l}\text { Private } \\
\text { Insurance } \\
\text { /Military }\end{array}$ & Medicare & $\begin{array}{l}\text { Medicaid } \\
*\end{array}$ & Uninsured** \\
\hline Medicaid Expanding $(\mathrm{n}=31)$ & 57.3 & 14.4 & 21.4 & 6.6 \\
Non-Medicaid Expanding $(\mathrm{n}=17)$ & 57.4 & 14.7 & 17.1 & 10.6 \\
$* * * \mathrm{P}=<0.01$ & & & & \\
\hline
\end{tabular}

Table 2: Sources of Insurance Coverage (\% of Population Covered by Payor, 2018) (Kaiser Family Foundation Statewide Insurance Tables, 2018) 


\begin{tabular}{|c|c|c|c|}
\hline & $\begin{array}{l}\text { Average Annual } \\
\text { Change in Lung } \\
\text { Cancer Screening } \\
\text { per } 1000 \text { Smokers } \\
(\%)\end{array}$ & & $\begin{array}{l}\text { Percentage of Studies } \\
\text { Considered } \\
\text { Appropriate by } \\
\text { USPSTF Criteria (\%) }\end{array}$ \\
\hline & Mean & $\begin{array}{l}\text { Standard } \\
\text { Deviation }\end{array}$ & Mean \\
\hline $\begin{array}{l}\text { Medicaid Expanding } \\
(\mathrm{n}=31)\end{array}$ & 57.6 & 46.5 & 89.6 \\
\hline $\begin{array}{l}\text { Non-Medicaid } \\
\text { Expanding }(\mathrm{n}=17)\end{array}$ & 50.3 & 23.4 & 90.2 \\
\hline
\end{tabular}

Table 3: Average Annual Change in Lung Cancer Screening per 1000 Smokers and Percentage of Studies Considered Appropriate by USPSTF Criteria 
